BLS 34, No 1 2008. DOI: http://dx.doi.org/10.3765/bls.v34i1.3566

(published by the Berkeley Linguistics Society and the Linguistic Society of America)

\title{
Event Integration Patterns in Sidaama (Sidamo) ${ }^{1}$
}

\author{
KAZUHIRO KAWACHI \\ Research Institute for Languages and Cultures of Asia and Africa, Tokyo \\ University of Foreign Studies, and Meiji Gakuin University
}

\section{Introduction}

This study examines how Sidaama (Sidamo), a Cushitic language of Ethiopia, expresses components of different types of events to test Talmy's (1985, 1991, 2000) typological hypotheses concerning event integration. It shows that although this language clearly exhibits the verb-framed language pattern in the event domains of motion, state change, and realization, it does not clearly exhibit this pattern in the domains of temporal contouring and action correlation.

The paper is organized as follows. Section 1 reviews Talmy's typology of event integration. Section 2 describes the ways that Sidaama expresses the different types of events that are relevant to this typology. Section 3 discusses the issues that the findings of the present study raise. Section 4 concludes the paper.

\section{Literature Review}

According to Talmy $(1991,2000)$, the cognitive process of event integration is the conceptual integration or conflation of an event as unitary that, more analytically, would be conceptualized as complex; in language, this process emerges as the expression of an event in a single clause that, more analytically, would be expressed by means of a more complex syntactic structure. Talmy argues that although languages can differ as to what can be conceptualized as single events and expressed in a single clause, there is a class of events that tend to be recurrently conceptualized as macro-events and expressed in single clauses across

\footnotetext{
${ }^{1}$ I would like to express my sincere thanks to Dr. Abebayehu Aemero Tekleselassie (K'eweena dialect) for the consultation sessions and discussions on various aspects of Sidaama over the years, and to Sileshi Workeneh (Alatta dialect), Solomon Shaamanna (Alatta dialect), and Yehualaeshet Aschenaki (K'eweena dialect) for being my consultants during my fieldwork in the Sidaama zone in March 2008. I am profoundly grateful to Dr. Leonard Talmy, Dr. Matthew S. Dryer, and Dr. Jürgen Bohnemeyer for their advice and comments on earlier versions of the present paper. Many thanks also go to Justin Boffemmyer for his valuable comments on this paper.

List of Abbreviations. ALL: Allative, CNN, Connective, COM: Comitative, EMPH: Emphatic, EP: Epenthetic vowel, INF: Infinitive, LV: Lengthened vowel.
} 


\section{Kazuhiro Kawachi}

languages. A macro-event is made up of two major components, a framing event and a co-event, as well as the support relation (e.g. manner, cause) of the co-event to the framing event. The framing event, which is the main event of a macro-event, constitutes the schematic component of the macro-event, and has a framing function relative to the macro-event. It "provides for the whole macro-event the overarching conceptual framework or reference frame within which the other included activities are conceived of as taking place", and represents "the upshot - relative to the whole macro-event" in the sense that "it is the framing event that is asserted in a positive declarative sentence, that is denied under negation, that is demanded in an imperative, and that is asked about in an interrogative"; moreover, it determines the overall temporal and spatial frameworks, the argument structure, and the syntactic complement structure (Talmy 2000:219).

The framing event consists of a figural entity, a ground entity, an association function, which associates the figural entity to the ground entity, and an activation process, which has the value of transition or fixity. The association function constitutes a core schema by itself (or together with the ground entity). Except for a realization event, which always requires an agent, a macro-event may or may not include an agent; if included in a macro-event, the agent might cause the framing event, the co-event, or both.

According to Talmy's typology of event integration, there are two major typological types, verb-framed languages (V-languages) (e.g. Romance languages) and satellite-framed languages (S-languages) (e.g. Germanic languages). V-languages typically encode the core-schematic component of a framing event in the predicate verb (framing verb), and express a co-event component (e.g. a specific manner) in an adverbial subordinate clause (or a non-predicate verb), whereas S-languages characteristically use a satellite (framing satellite) to express the core-schematic component of a framing event, and encode the co-event component in the verb root. This contrast applies not only in the event domain of motion, but also in four other domains: state change, realization, temporal contouring, and action correlation.

As mentioned above, the core schema of a framing event is called the association function, which associates the figure entity with the ground entity. (1) (adapted from Talmy 2000:214) lists the association function of each type of event in square brackets (i.e. [ ]). In an S-language, the association function is expressed with a satellite, whereas the co-event is expressed with a predicate verb, as shown in the English examples of each of the five event domains after the square brackets in (1), where the satellite is in italics.

a. motion [association function: path] e.g. The ball rolled in.

b. state change [association function: transition type (entry into a state, departure from a state, lack of transition)] e.g. The candle blew out.

c. realization [association function: (confirmation of the implicature of) the fulfillment of the agent's goal] e.g. The police hunted the fugitive down. 
d. temporal contouring [association function: aspect (e.g. continuation, completion, repetition)] e.g. They talked on.

e. action correlation [association function: correlation of one action with respect to another] e.g. I sang along with him.

In a V-language, on the other hand, the association function is expressed by a predicate verb, whereas the co-event is expressed by a non-predicate verb or adverbial.

There are many single-language and cross-linguistic studies on motion (e.g. Aske 1989, Slobin 1996, Im 2001, Brown 2003, Zlatave \& Yangklang 2003, Bohnemeyer et al. 2007) $)^{2}$ and some studies on state change and realization (e.g. Levin \& Rappaport Hovav 1996) that have used or tested Talmy's typology of event integration, but there seem to be few studies that have been conducted in terms of his typology specifically on expressions of temporal contouring and action correlation in a particular language or across languages aside from his own research. Moreover, there seem to be no studies that have looked at any Cushitic languages under this framework. Thus, the present study is novel in that what it examines are the patterns of expressing all five event domains in an African language.

\section{Event Integration Patterns in Sidaama}

Sidaama is a Highland East Cushitic language spoken in South Central Ethiopia (Kawachi 2007). The case system of this language is accusative. It is a verb-final language whose word order is predominantly SOV, and uses suffixation (and also suprafixation for marking some grammatical cases).

This language has two types of multi-verb constructions. One is the temporal sequence construction, which takes the form V1-PERS-e V2 (or less commonly, forms with more than two non-predicate verbs), where the non-predicate verb takes (or the non-predicate verbs each take) the connective suffix $-e$ as well as a person suffix, and the predicate verb takes another type of person suffix and the aspect suffix (and the gender suffix as well in the case of the first- and second-person singular). ${ }^{3}$ This construction is used to indicate that the event component expressed by the non-predicate verb precedes (or those expressed by the non-predicate verbs precede) that expressed by the predicate verb. The other type of construction has the form, V1-PERS-a-nni V2, where the non-predicate verb takes the infinitive suffix $-a$ and the manner/concomitance or instrumental suffix $-n n i$ in addition to the same type of person suffix as the one used for the

\footnotetext{
${ }^{2}$ However, despite their large number, even studies on motion tend to include only the manner of motion (and sometimes the cause of motion, at most) in the relation of a co-event to the framing event in a motion macro-event, and to argue against the essence of Talmy's typology with minor counterexamples from manner of motion expressions without taking any other type of co-event into consideration.

${ }^{3}$ Henceforth, the temporal sequence construction will be treated as if it always had only two verbs, V1 (the non-predicate verb) and V2 (the predicate verb).
} 


\section{Kazuhiro Kawachi}

non-predicate verb in the temporal sequence construction, and the predicate verb takes another type of person suffix and the aspect suffix (and the gender suffix as well for the first- and second-person singular). It has one of the following three interpretations, depending on the combination of the types of the verbs used: (i) the manner/concomitance interpretation ('V2 with the manner or concomitance of V1'), (ii) the extended causation interpretation ('V2 by doing V1 continuously'), or (iii) the 'while' interpretation ('while V1, V2').

The present section shows that Sidaama clearly exhibits the V-language pattern in expressing motion, state change, and realization events, but it often does not follow this pattern in expressing temporal contouring and action correlation events. Note that what is of concern here is what grammatical categories Sidaama uses to express the different components of the five types of events, and neither the question of the definition of a macro-event nor that of single-clausehood in Sidaama are brought up, though they are very important issues (see Kawachi 2007).

\subsection{Motion}

Sidaama basically shows the V-language pattern in expressing motion macro-events. Either of the multi-verb construction types can be used where V1 expresses a co-event and V2 expresses a path. Which construction is used depends on the type of co-event. When the co-event is a manner of motion, although there are limited cases where manner of motion verbs can take path expressions directly without any path of motion verb (Kawachi 2007, in press), either of the two constructions can usually be used with almost no difference in meaning in most cases, as in (2), except that the manner tends to be more emphasized in the manner/concomitance construction than in the temporal sequence construction.

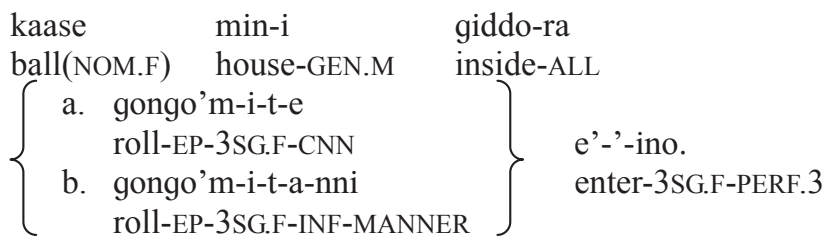

'The ball rolled into the cave.' (Lit. a. 'The ball rolled and entered the house.' / b. 'The ball entered the house, rolling.')

When the co-event is in a concomitance relation to the framing event of motion, one of the multi-verb constructions in which V2 is a path of motion verb is used depending on the type of V1, which expresses the cause of motion; the manner/concomitance construction is used if V1 is an action verb (e.g. 'to whistle' in 'He passed by me, whistling.'), and the temporal sequence construction is used if V1 is a state-change verb (e.g. 'to lean' in 'He left, with his body leaning to one side.'). For a motion event where the co-event has the relation of a cause to the 


\section{Event Integration Patterns in Sidaama (Sidamo)}

framing event (e.g. 'She kicked the ball across the field.'), the temporal sequence construction with the cause of motion expressed by V1 and the path expressed by V2 is often used, but if such a motion event involves extended causation (e.g. 'She kicked the ball across the field.' when her kicking the ball continues across the field), the extended causation construction is used. When the co-event is in a precursion (e.g. 'I locked him in the house.') or enablement (e.g. 'He opened the door, and entered.') relation to the framing event of motion, the temporal sequence construction is often used, where the co-event appears in V1 and the path in V2.

Whatever relation the co-event bears to the framing event, and whichever of the two types of constructions is used for a motion event, V2 normally expresses the path. Thus, Sidaama basically follows the V-language pattern with respect to this event type.

\subsection{State Change}

Sidaama also clearly shows the V-language pattern in state change expressions. It expresses the core schema (with the association function being a transition type and the ground entity being the changed property) with a predicate verb, and a co-event often expressed by V1 of one of the multi-verb constructions, as in (3a), (4a), and (4b), or occasionally with an adjunct, as in (3b).

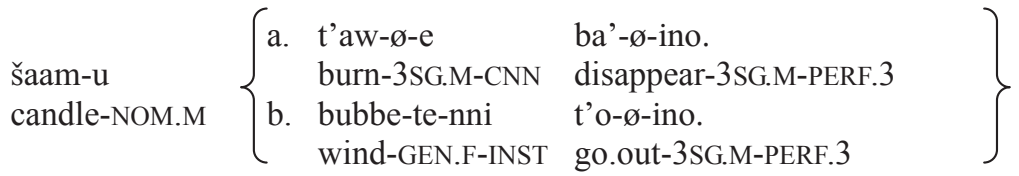

a. 'The candle burned out.' (Lit. 'The candle burned and disappeared.')

b. 'The candle blew out.' (Lit. 'The candle went out by the wind.')

$\begin{array}{ll}\text { isi } & \text { uddanó } \\ \text { 3SG.M.NOM } & \text { clothes(ACC) }\end{array}\left\{\begin{array}{ll}\text { a. } & \begin{array}{l}\text { huunč'- } \varnothing-\mathrm{e} \\ \text { squeeze-3SG.M-CNN } \\ \text { b. } \\ \text { huunč'- } \varnothing-\text {-a-nni } \\ \text { squeeze-3SG.M-INF-INST }\end{array}\end{array}\right\}$

mool-s-ø-ino.

become.dry-CAUS-3SG.M-PERF.3

a. 'He squeezed the clothes (usually, one time), and then dried them.'

b. 'He dried the clothes by squeezing them (multiple times at certain intervals).'

\subsection{Realization}

Also for realization events, which Talmy (2000:271) points out could be regarded as a special type of (agentive) state change events, Sidaama basically follows the V-language pattern. It usually uses the temporal sequence construction, where V2 expresses the association function of the fulfillment of the agent's goal or the confirmation of its implicature, and V1 expresses the co-event of its cause. For example, in (5), the agent's action of hunting, which does not imply the 


\section{Kazuhiro Kawachi}

fulfillment of the goal, appears as V1, and the fulfillment of his intention to catch the thief is expressed in V2.

$$
\begin{array}{lccc}
\text { isi } & \text { moorančó } & \text { ugaat'- } \varnothing-\mathrm{e} & \text { amad- } \varnothing \text {-ino. } \\
\text { 3SG.M.NOM } & \text { thief(ACC) } & \text { hunt-3SG.M-CNN } & \text { catch-3SG.M-PERF.3 } \\
\text { 'He hunted the thief down.' (Lit. 'He hunted for and caught the thief.') }
\end{array}
$$

\subsection{Temporal Contouring}

The semantic domain of temporal contouring consists of various aspectual categories. Sidaama may use framing verbs for (i) completion/termination and (ii) initiation, but not for (iii) continuation, (iv) habitualness, (v) repetition, (vi) gradualness, or (vii) frequency. In a macro-event in any of these categories, the support relation that the co-event has in relation to the framing event is "a constitutive relation, in effect 'filling in' the conceptual region outlined by the temporal contour" (Talmy 2000:232).

(i) Completion/termination: There are a few verbs for completion/termination that are used as V2 of the temporal sequence construction; the transitive verbs, gud- 'to finish (doing a bounded action)' and $\mathrm{ka}$ '- 'to finish (doing an unbounded action)', often serve as framing verbs, and the intransitive verb, goof- 'to come to an end (often, after consumption)', may also be used this way in some contexts. There is also a verb of (usually, permanent) termination, agur- 'to stop doing', that takes the infinitive form. The completion of an action or state change can also be expressed by two types of perfective suffixes on the verb, which are interchangeable with each other without any difference in meaning in most cases when attached to predicate verbs, and do not differ very much except that one is more likely to be used than the other when the completion is relatively close to the moment of utterance.

(ii) Initiation: Sidaama can use a verb of initiation borrowed from Amharic, jammar - 'to start to do', which takes the infinitive form. There is also a construction that is used for the initiation sense of 'to be about to do'; it takes the form of V-a-PERS(-GENDER)-ra or V-PERS- $a$-ra, where a verb is accompanied by the infinitive suffix $-a$, the person suffix, (the gender suffix), and the dative suffix -ra. This infinitive-dative form of a verb can be followed by the verb $\mathrm{ka}^{\prime}-$, which is also used for completion or termination, as mentioned above, or the noun-phrase clitic $=t i$, to express 'be about to do'. It can also be followed by the verb $y$ - 'to say' with the person suffix and the infinitive suffix in a subordinate clause ending with the suffix -nni 'while' or the clitic =nna 'and, while' to express 'when someone/something is about to do (something)'. Sidaama also has one verb that lexicalizes initiation: $t$ 'int- 'to start to build a house/plait a basket', though it is used exclusively for one of these two actions, and takes as its object either of the nouns, mine 'house' or saffe 'savanna grass container', but not any other noun.

(iii) Continuation: Continuation can be expressed with aspectual constructions or with lexical verbs. The two aspectual constructions, the continuous aspect 
construction ('have been doing something/in a state') and the present progressive construction (with an action verb: 'be doing something'), both use the existential/locational verb as V2 of the temporal sequence construction and the manner/concomitance construction, respectively. Sidaama also has three verbs that lexicalize continuation: hos- 'to spend all day doing', gal- 'to spend all night doing', and keešš- 'to stay long in one place doing', which are each often used as V2 of the temporal sequence construction. Nevertheless, continuation per se is not expressed by a framing verb.

(iv) Habitualness: There is no verb root that conveys habitualness. This aspectual notion is expressed with the imperfect suffix on the verb (e.g. insa adó ag-g-anno [3PL.NOM milk(ACC) drink-3PL-IMPERF.3] 'They (habitually) drink milk.'), an adverbial like the following, or both: duučča wote [all time] 'every day, all the time', wo'ma-nka wote [all-EMPH time] 'always', wo'ma-nka yanna/duučča-nka yanna [all-EMPH time] 'always', barro barr-u-nni [day day-GEN.M-INST] 'every day', duučča(-nka) barra [all(-EMPH) day] 'every day', hašša hašša [evening evening] 'every evening', hašša hašš-u-nni [evening evening-GEN.M-INST] 'every evening', dir-u duučča [year-GEN.M all] 'every year', dir-u baala [year-GEN.M total] 'every year'.

(v) Repetition: Repetition can be expressed by the verb hig- 'to return' or k'ol'to turn, return' used as the non-predicate verb of the temporal sequence construction (hig-PERS-e or k'ol-PERS-e 'again'), by its reduplication (hig-PERS-e hig-PERS-e or k'ol-PERS-e k'ol-PERS-e 'again and again'), or by the reduplicated form of the verb rak- 'to hurry' used as the non-predicate verbs of the temporal sequence construction (rak-PERS-e rak-PERS-e 'again and again'). There is also an idiomatic adverbial for 'one after another': aana aana-ho [top top-LOC.M]. In any of these cases, the repeated action, that is, the co-event of repetition, appears as the predicate verb.

The repetition of an action might also be expressed by the reduplication of a verb (e.g. šaf- 'to shake'/šaššaf- 'to shake repeatedly', gan- 'to hit'/gangan- 'to beat'). In this case, the repeated action is expressed by the verb root, while the repetition is indicated by the morphological process of reduplication.

(vi) Gradualness: When the verb is a state change verb, gradual state change ('be in the process of entering a state') can be expressed in the present-progressive aspect construction, which uses the existential/locational verb as V2 of the manner/concomitance construction and a state change verb as its V1. Gradualness can also be expressed by an adverbial that is in the form of V1 of the temporal sequence construction (sununni (sununni) $y$-/ass-/ikk-PERS-e [slowly (slowly) say-/do-/become-PERS-CNN] 'gradually', šiima šiima ass-PERS-e [small small do-PERS-CNN] 'gradually') or an oblique NP adverbial (e.g. yanna yanna-te-nni [time time-GEN.F-ABL] 'gradually', bero-nni teččo [yesterday-ABL today] 'gradually', aana aana-ho [top top-LOC.M] 'one after another' (for a state-change of a group of objects)). Although Sidaama has a large class of state change verbs, the gradualness of a change is not expressed by a verb root.

(vii) Frequency: Sidaama has adverbials for different levels of frequencies of 


\section{Kazuhiro Kawachi}

actions (yanna yanna-te-nni [time time-GEN.F-ABL] 'from time to time', horonta/horonka/horñanka/takkonta 'never', duučča-nka-wote/wo'ma-nka-wote [all-EMP-time] 'frequently, almost always'). It can also reduplicate the form of the verb $s a$ '- 'to pass' used as the non-predicate verbs of the temporal sequence construction to express 'sometimes' ( $s a$ '-PERS-e sa'-PERS-e [pass-PERS-CNN pass-PERS-CNN]). In either case, the co-event, namely the action depicted as occurring with a particular frequency, appears in the predicate verb.

\subsection{Action Correlation}

The event category of action correlation concerns what Talmy (2000:253) calls 'coactivity', where one Agent performs an activity in correlation with a (usually) same-category action performed by another entity, an Agency (either animate or inanimate). As in a macro-event of temporal contouring, with action correlation, the co-event is in a constitutive support relation to the framing event, where the figure is the Agent's action, the ground is the Agency's same or same-category action (or the Agency's complementary action in the case of 'demonstration'), and the association function is the correlation of one action with respect to another. There are five subtypes of action correlation: 'concert' ('act in concert with NP at V-ing'), 'accompaniment' ('act in accompaniment of/as an adjunct to, accompany/join (in with) NP at V-ing'), 'imitation' ('V in imitation of NP, imitate/copy NP at V-ing'), 'surpassment' ('surpass/best/beat NP at V-ing'), and 'demonstration' ('demonstrate to NP one's V-ing'). In the first four, the Agent and the Agency perform the same or same-category actions, whereas in 'demonstration', they perform different-category actions.

Out of the five action correlation categories, Sidaama deviates from the V-language pattern in expressing four of them, (i) concert, (ii) accompaniment, (iii) imitation, and (iv) surpassment, though it uses a predicate verb for the other category, (v) demonstration.

(i) Concert: The action correlation notion of concert, where the Agent and the Agency are both engaged in a joint activity, each making a contribution of equal importance to the whole, is expressed, not by a framing verb, but by an oblique NP constituent, as in (6) and (7a), or by an idiomatic expression, as in (7b), that serves as V1 of the temporal sequence construction.

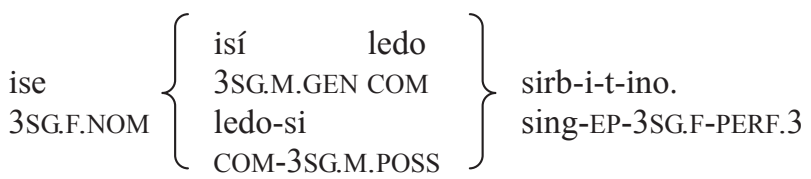

'She sang together with him.'

\begin{tabular}{|c|c|c|c|}
\hline ise $=$ nna & isi & $\begin{array}{l}\text { a. mitte-e-nni } \\
\text { one.F-LV-INST }\end{array}$ & dikkó \\
\hline 3SG.F.NOM=and & 3SG.M.NOM & $\begin{array}{l}\text { b. ikk-i-t-e } \\
\text { become-EP-3PL-CNN }\end{array}$ & market(OBL) \\
\hline
\end{tabular}




\section{Event Integration Patterns in Sidaama (Sidamo)}

had-d-ino.

go-3SG.L-PERF.3

a. \& b.: 'She and he went to the market together.'

(ii) Accompaniment: Sidaama does not have any expression that is devoted to the notion of accompaniment, where the Agent's action is secondary or additional to the Agency's action. For this category, a construction using the comitative noun ledo such as in (6) may be casually used, or a two-clause construction with the conjunctive clitic =nna, where the Agency's action expressed in the subordinate clause serves as the ground, may be used as in (8). Thus, the construction as a whole can be regarded as expressing accompaniment, but the co-event appears in the verb of the main clause.

$$
\begin{array}{lll}
\text { ise } \quad \text { dod-d-a }=\text { nna } & \text { isi }=\text { no } & \text { dod-ø-ino. } \\
\text { 3SG.F.NOM run-3SG.F-INF=while } & \text { 3SG.M.NOM=also } & \text { run-3SG.M-PERF.3 } \\
\text { 'While she ran, he also ran.' } & &
\end{array}
$$

Sidaama does not have a verb that specifically refers to 'to join'. The verb $t$ 'aad'to meet, join' could be used, but the event may be interpreted as the Agent's meeting with the Agency or the Agent's joining with the Agency.

(iii) Imitation: The framing event of imitation also appears in an adverbial rather than in a predicate verb. The verb ikk- 'to become' is used as V1 of the temporal sequence construction to literally mean ' $\mathrm{X}$ becomes $\mathrm{Y}$, and V2', as in (9).

$$
\begin{array}{llll}
\text { isi } & \text { isé } & \text { ikk- } \varnothing-\mathrm{e} & \text { sirb- } \varnothing \text {-ino. } \\
\text { 3SG.M.NOM } & \text { 3SG.F.OBL } & \text { become-3SG.M-CNN } & \text { sing-3SG.M-PERF.3 } \\
\text { 'He sang in the imitation of her.' (Lit. 'He became her, and sang.') }
\end{array}
$$

Although the verb ikk- could be used as a predicate to express one entity's equality or similarity with another (e.g. isi isé ikk-ø-ino. [3SG.M.NOM 3SG.F.OBL become-3SG.M-PERF.3] 'He became equal/similar to her (with respect to e.g. height, behavior, appearance, wealth, etc.).'), Sidaama does not have any construction that uses a verb for imitation as a predicate.

(iv) Surpassment: For a type of surpassment, Sidaama can follow the V-language pattern; it can use the temporal sequence construction in which V2 expresses the schematic core of the framing event of surpassment and V1 expresses a co-event, as in (10). However, this is limited to a racing context.

$$
\begin{aligned}
& \text { ise isó daak-k-e k'olč-i-t-anno. } \\
& \text { 3SG.F.NOM 3SG.M.ACC swim-3sG.F-CNN } \text { outdistance-EP-3SG.F-IMPERF.3 } \\
& \text { 'She swims faster than him.' (Lit. 'She swims and outdistances him.') }
\end{aligned}
$$

In other contexts, Sidaama does not follow the V-language pattern. As in (11), the 


\section{Kazuhiro Kawachi}

notion of surpassment shows up as an adverbial or V1 of the temporal sequence construction, and a co-event appears as the predicate verb.

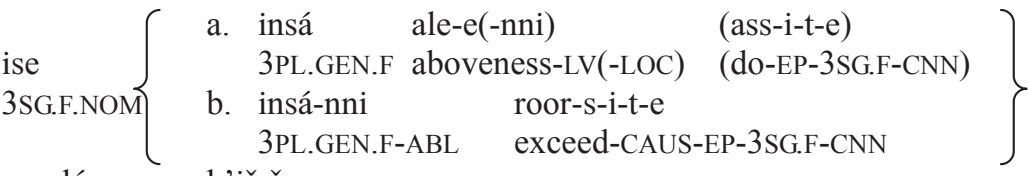

$$
\begin{aligned}
& \text { sagalé k'iš-š-anno. } \\
& \text { food(ACC) cook-3sG.F-IMPERF.3 }
\end{aligned}
$$

'She cooks better than them.' (Lit. a. 'She (does) above them (and) cooks food.' / b. 'She exceeds them and cooks food.')

(v) Demonstration: For the framing event of demonstration, Sidaama has two verbs that can be used as predicates: $r o s-i-S$ - [learn-EP-CAUS-] 'to teach, show (for the purpose of teaching)' and leell-i- ̌s- [become.visible-EP-CAUS-] 'to show, demonstrate'. They are used as in (12), and neither of them uses either of the multi-verb constructions.

$$
\begin{aligned}
& \text { ise isó/isí-ra hiitto } \\
& \text { 3SG.F.NOM 3SG.M.ACC/3SG.M.GEN-DAT.PRON how } \\
& \begin{array}{l}
\text { sirb-i-n-a-nni-gede } \\
\text { sing-EP-how.to-INF-INST-like }
\end{array}\left\{\begin{array}{l}
\text { leell-i-š-š-ino. } \\
\text { become.visible-EP-CAUS-3SG.F-PERF.3 } \\
\text { ros-i-s-s-ino. } \\
\text { learn-EP-CAUS-3SG.F-PERF.3 }
\end{array}\right\}
\end{aligned}
$$

'She demonstrated to him how to sing.'

\section{Discussion}

As described in the previous section, Sidaama clearly shows the V-language pattern in the three event domains of motion, state change, and realization, but often does not in the other two event domains of temporal contouring and action correlation. There are different factors that might contribute to such a deviation of this language from the typological pattern.

First, though not as sharp as in Sidaama, similar deviations are found at least in Japanese and Korean, and Sidaama might constitute a subtype of V-languages with these languages, differently from Romance languages, which Talmy demonstrates exhibit the V-language pattern in all five domains. For example, Japanese normally does not use a framing verb for the temporal contouring categories of habitualness, gradualness, and frequency, or for the action correlation categories of concert and surpassment, though it may use a framing verb for other categories of temporal contouring and action correlation. Talmy's findings on the V-language pattern in expressing temporal contouring and action correlation are based mainly on Romance languages, and it might be possible that other subtypes of V-languages do not necessarily follow the V-language pattern in expressing events in these domains. 
Second, the deviation of Sidaama and other languages from the V-language pattern in the semantic domains of temporal contouring and action correlation may be due to the diversity of their categories. These semantic domains are miscellaneous (for example, the figure and ground entities in these semantic domains vary depending on the category, unlike in the other three semantic domains), though the co-event is invariantly constitutiveness, and the categories of each of the semantic domains might differ as to how the typological difference is relevant; in other words, languages may be more likely to show the V-language pattern in some categories of these semantic domains than in others.

Third, the deviation may occur because the framing events of the two semantic domains are too abstract. Compared to the framing events of motion, state-change, and realization, those of temporal contouring and action correlating seem to be very abstract, perhaps to the extent that it is difficult to represent "the upshot - relative to the whole macro-event" (Talmy 2000:219) without a co-event expressed. In the case of motion, state-change, and realization, the expression of the framing event, as in the English examples The ball went down. I The candle went out. / The police captured the fugitive, by itself, can be a complete description of what has happened, even if no co-event is mentioned at all. On the other hand, in the case of temporal contouring and action correlating, the expression of the framing event alone cannot be an informative description of what has happened, when used out of context, as in the English examples She continued (to do something). / She finished (doing something). / She did (something) together/along with him. / She did (something) in the imitation of him. Thus, a co-event needs to be mentioned to convey the upshot of the whole event. In other words, the existence of a co-event is required in these event categories. As an obligatorily used constituent, a verb may be used for this purpose. If a verb is employed for the co-event, a non-verbal constituent can appear to express the framing event. An S-language can do this easily with a satellite. On the other hand, a V-language may have to express the framing event with an adverbial or a non-predicate verb of a multi-verb construction, and deviate from the prototypical V-language pattern.

Nevertheless, all these are mere speculation, and detailed research on other V-languages is awaited.

\section{Conclusion}

As shown so far, although it follows the V-language pattern described by Talmy closely in expressing the event domains of motion, state change, and realization, Sidaama deviates from this pattern in its expressions of some types of temporal contouring and of most types of action correlation, just as at least a few other languages that are also classified as V-languages do. An investigation of how other V-languages express temporal contouring events and action correlation events might make it possible to find further typological sub-classification. 
Kazuhiro Kawachi

\section{References}

Aske, Jon. 1989. Path Predicates in English and Spanish: A Closer Look. Proceedings of the 15th Annual Meeting of the Berkeley Linguistics Society, 1-14. Berkeley: Berkeley Linguistics Society.

Bohnemeyer, Jürgen, Nicholas J. Enfield, James Essegbey, Iraide Ibarretxe-Antuñano, Sotaro Kita, Friederike Lüpke, and Felix K. Ameka. 2007. Principles of Event Segmentation in Language: The Case of Motion Events. Language 83(3): 495-532.

Brown, Penelope. 2003. Position and Motion in Tzeltal Frog Stories: The Acquisition of Narrative Style. In Strömqvist, Sven, and Ludo Verhoeven, eds., Relating Events in Narrative, Volume 2: Typological and Contextual Perspectives, 37-57. Mahwah, NJ: Erlbaum.

Im, Sung-chool. 2001. Typological Patterns of Motion Verbs in Korean. Ph.D. diss., University at Buffalo, State University of New York.

Kawachi, Kazuhiro. 2007. A Grammar of Sidaama (Sidamo), a Cushitic Language of Ethiopia. Ph.D. diss., University at Buffalo, State University of New York.

Kawachi, Kazuhiro. In press. Manner of Motion Verbs in Sidaama and Boundary Crossing. Proceedings of the 43rd Annual Meeting of the Chicago Linguistic Society (2007), Volume 2: Panels. Chicago: Chicago Linguistic Society.

Levin, Beth, and Malka Rappaport Hovav. 1996. Lexical Semantics and Syntactic Structure. In Shalom Lappin, ed., The Handbook of Contemporary Semantic Theory, 487-507. Oxford: Blackwell.

Slobin, Dan I. 1996. Two Ways to Travel: Verbs of Motion in English and Spanish In Masayoshi Shibatani and Sandra A. Thompson, eds., Grammatical Constructions: Their Form and Meaning, 195-220. Oxford: Clarendon Press.

Talmy, Leonard. 1985. Lexicalization Patterns. In Timothy Shopen, ed., Language Typology and Syntactic Description, vol.3: Grammatical Categories and the Lexicon, 57-149. Cambridge: Cambridge University Press.

Talmy, Leonard. 1991. Path to Realization: A Typology of Event Conflation. Proceedings of the 17th Annual Meeting of the Berkeley Linguistics Society, 480-519. Berkeley: Berkeley Linguistics Society.

Talmy, Leonard. 2000. Toward a Cognitive Semantics, Volume II: Typology and Process in Concept Structuring. Cambridge, MA: MIT Press.

Kazuhiro Kawachi

Research Institute for Languages and Cultures of Asia and Africa,

Tokyo University of Foreign Studies

3-11-1 Asahi-cho, Fuchu-shi, Tokyo 183-8534

Meiji Gakuin University

1518 Kamikurata-cho,

Totsuka-ku, Yokohama-shi

Kanagawa 244-8539 Japan

kazuhirokawachi@gmail.com,kazuhirokawachi@hotmail.com 